\title{
Subcutaneous emphysema and pneumomediastinum complicating labor in a twin pregnancy
}

\author{
MICHAEL LOUIS SPARACINO, CAPT, USAF, MC \\ PETER EHRLICH MACKAY, CAPT, USAF, MC
}

\begin{abstract}
Although a rare complication of labor, subcutaneous emphysema and pneumomediastinum (Hamman's syndrome) must be considered in the parturient complaining of chest or neck pain, dysphagia, or shortness of breath. With conservative management, the prognosis is favorable. The case presented is the first of Hamman's syndrome complicating the labor of a twin gestation. The pathophysiology, symptoms, and management guidelines for the syndrome are reviewed.
\end{abstract}

Pneumomediastinum and subcutaneous emphysema (Hamman's syndrome) are rare complications of pregnancy; incidence estimates range from $1: 2,000^{1}$ to $1: 100,000 .^{2}$ The world literature includes 190 cases to date. ${ }^{3,4}$

The first reference to what may have been this syndrome was made in 1618 by the midwife to the queen of France, who wrote, "I saw that she tried to stop crying out and I implored her not to stop for fear that her neck might swell." ${ }^{4}$ It was not until 1784 that Simmons ${ }^{5}$ reported the first case of pneumomediastinum and subcutaneous emphysema associated with labor.

A review of 130 cases by Gordon ${ }^{6}$ in 1927 indicated that most patients were primiparous, that the syndrome developed during the second stage of labor, and that most cases were associated with prolonged labor. Reeder, ${ }^{3}$ in his 1986 review of 187 cases, agreed with Gordon's first two conclusions but stated that, by modern criteria, most of the first and second stages were of normal duration. Additionally, delivered infants were of average size.

We describe the first case of Hamman's syndrome ${ }^{12}$ complicating a twin pregnancy. Symptoms, signs, and pathophysiology of the disease are presented, and treatment guidelines are suggested.

\section{Report of cases}

With an estimated date of confinement of March 22, 1986, a 24-year-old gravida 1, para 0 woman with an ultrasonographic-confirmed twin gestation but otherwise unremarkable prenatal course presented at $3 \mathrm{PM}$ on March 21. She complained of contractions at sevenminute intervals; these had begun 18 hours prior to admission. She denied fever, chills, abdominal pain, vaginal bleeding, spontaneous rupture of membranes, cough, and respiratory distress. She had been hospitalized at 31 weeks' gestation for observation and bedrest to prevent labor.

The admission head and neck examination was unremarkable. The lungs were clear, and breath sounds were normal bilaterally. Cardiovascular examination was within normal limits. Her abdomen was gravid, with both twins in the vertex presentation and the left twin in the inferior position. Both fetal heart tones were in 150 per minute range. The cervix was $5 \mathrm{~cm}$ dilated, soft, anterior, and $90 \%$ effaced, and the vertex was at -2 station.

The patient was dilated completely by $4: 30 \mathrm{PM}$. The second stage of labor proved difficult; it required vigorous pushing and intravenous administration of oxytocin. Aided by low-outlet forceps and third-degree midline episiotomy, the first female twin, weighing $5 \mathrm{lb} 14 \mathrm{oz}$, was delivered at $6: 36 \mathrm{PM}$. The second female twin, weighing $8 \mathrm{lb} 7 \mathrm{oz}$, was delivered similarly at 7:00 PM. Apgar scores for the first baby were 7 and 8 at 1 and 5 minutes, respectively, while the second twin's scores were 8 and 9 , respectively. 
After delivery, the patient received a local infiltration of Xylocaine, and episiotomy repair was begun. During the procedure, she noticed neck and chest discomfort but did not alert the staff until three hours later, when she complained of substernal chest discomfort, dysphagia, and mild shortness of breath.

On examination, she was in moderate distress. The lung fields were clear, but these were mildly diminished breath sounds over the right hemithorax and fine crepitance to palpation along both lateral margins of the neck, bilateral supraclavicular areas, and the sternum. Heart rate was regular, with normal heart sounds.

Chest roentgenography revealed pneumomediastinum and marked soft-tissue air extending from the cervical region to the anterior chest and abdominal wall (Figs 1,2). An electrocardiogram was normal.

The patient was transferred to the intensive care unit for close observation. By the third postpartum day, she was asymptomatic and had partial resolution of the subcutaneous emphysema. No further problems were observed, and she was discharged on the fifth postpartum day. There have been no further complications.

\section{Discussion}

\section{Pathophysiology}

Pneumomediastinum may be classified etiologically as follows ${ }^{7}$ : Rupture of marginal alveoli into pulmonary interstitial tissue, then to the mediastinum; air entering the mediastinum from deeptissue planes in the neck or from the retroperitoneal space; perforation of the trachea, bronchus, or esophagus into the mediastinum; or mixed etiologic factors, such as spontaneous pneumomediastinum or chest wall trauma.

A mechanism of injury in the development of pneumomediastinum was hypothesized by Macklin and Macklin. ${ }^{8}$ They maintain that alveoli adjacent to blood vessels rupture from increased intraalveolar pressure, which results in pressure gradient in the perivascular sheath. Following the path of least resistance, the air makes its way toward the hilus. Air then dissects via tissue planes to subcutaneous areas in the face, neck, supraclavicular region, chest, and abdominal walls. Retroperitoneal areas may be affected similarly. If air passes between visceral and parietal pleura, pneumothorax results.

During labor, prolonged, intense Valsalva's maneuvers against a diaphragm immobilized by the gravid uterus could generate sufficient pressures to cause alveolar rupture in some patients. ${ }^{9} \mathrm{Be}$ cause most patients develop the syndrome during the second stage of labor, this mechanism could account for the majority of cases. ${ }^{10}$

\section{Symptoms and signs}

The type and severity of symptoms depend on the degree of compression of the lungs and me-
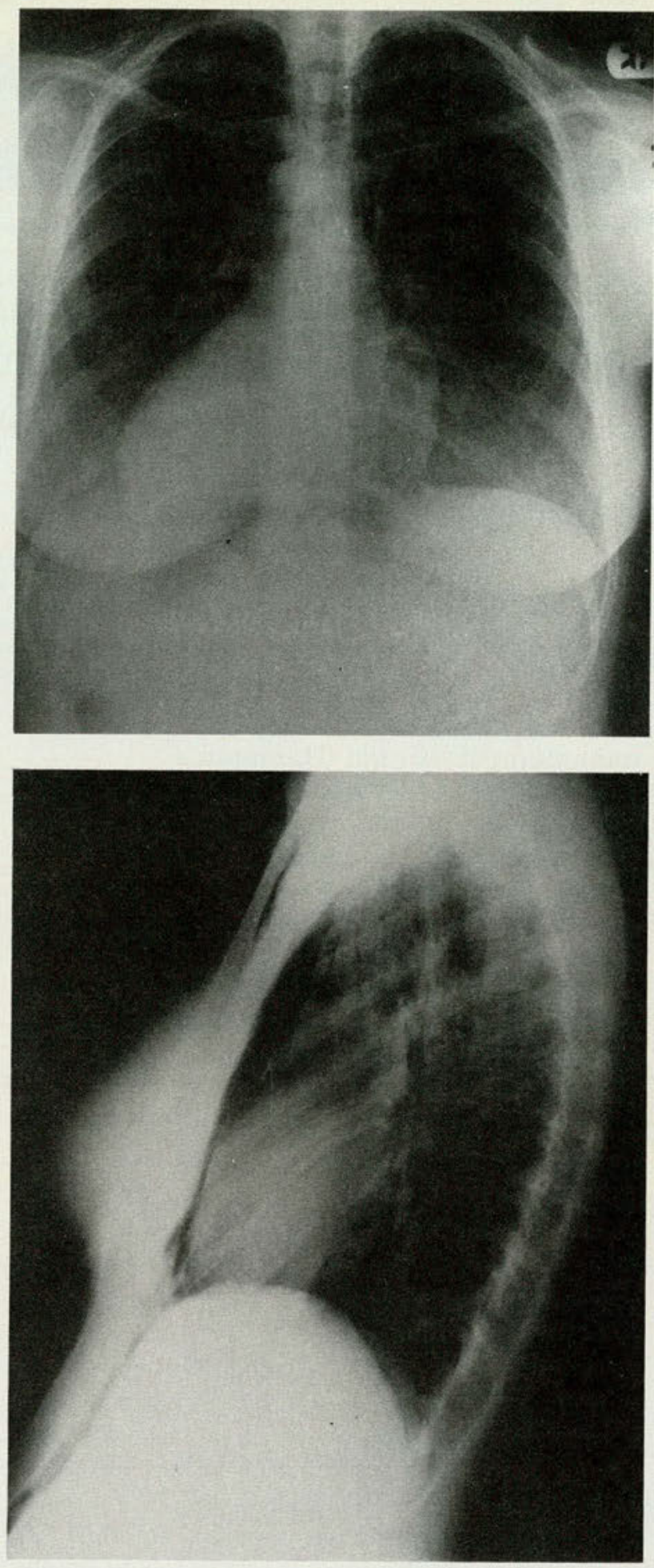

Figs 1, 2. Posteroanterior chest film (Fig 1) obtained during inspiration demonstrates pneumomediastinum and marked softtissue air in the neck region. Lateral view (Fig 2) shows softtissue air subcutaneously along the sternum and anterior abdominal wall.

diastinum, the air dissection pattern, and the final location of the dissected air. The most common symp- 
tom is chest pain, which is characterized as sharp, stabbing, or squeezing and severe in intensity, with variable radiation to the neck, shoulders, or back. The pain may be worse in the left lateral recumbent position, and sitting or leaning forward may alleviate the pain. Duration of pain may be from minutes to days. Other symptoms include dysphonia, aphonia, dysphagia, dyspnea, cough, swelling (which may become severe), sore throat, anxiety, hemoptysis, palpitations, shortness of breath, and crackling sounds in the chest. ${ }^{3,9,11,12}$

Four diagnostically important clincal signs include mediastinal crepitation, decreased or obliterated cardiac dullness, subcutaneous emphysema, and pneumothorax. ${ }^{13}$

The specific finding of crepitance in synchrony with the heart beat (Hamman's sign) is present only on occasion. ${ }^{9}$ This finding is elicited most easily with the patient in the left lateral recumbent position during end expiration and can be detected phonocardiographically. ${ }^{14}$ Hyper-resonance over the sternum is best elicited with the patient upright. ${ }^{9}$

About $25 \%$ of patients show electrocardiographic changes, but no consistent pattern has been demonstrated. Significant abnormalities include T wave changes (especially inversion), deviation of the ST segment, decreased voltages, and shifts in electric axis. ${ }^{15}$ Roentgenographic findings may include pneumomediastinum, subcutaneous air, and pneumothorax. ${ }^{16}$

\section{Management}

In most cases, symptomatic treatment with bed rest, oxygen, and analgesics will suffice. If pneumomediastinum persists or enlarges, mediastinotomy may be indicated. Although pneumothorax is unusual and frequently resolves spontaneously, chest tube insertion may be required. ${ }^{17}$ Prognosis is excellent, but two deaths have been reported. ${ }^{18}$

\section{Summary}

The first case of subcutaneous emphysema and pneumomediastinum complicating the labor of a twin gestation is reported. The case is characteristic in that the patient had been previously healthy, the second stage of labor was prolonged and difficult, and the patient complained of chest pain, shortness of breath, and dyspnea.
Examination revealed subcutaneous crepitance to palpation and slightly diminished breath sounds. Radiographic findings were characteristic. The patient recovered with conservative management and no sequelae have been reported.

Hamman's syndrome should be suspected in the parturient who complains of chest pain, shortness of breath, or dysphagia or who has facial or nuchal swelling.

1. Kosmak GW: Subcutaneous emphysema following labor, letter. Surg Gynecol Obstet 1925;40:434.

2. Kobak AJ, Abrams RH: Pregnancy complicated by massive subcutaneous emphysema of mediastinal origin (Hamman's syndrome). Am J Obstet Gynecol 1949;47:789-792.

3. Reeder SR: Subcutaneous emphysema, pneumomediastinum, and pneumothorax in labor and delivery. Am J Obstet Gynecol 1986;154:487-489.

4. Karson EM, Saltzman D, Davis MR: Pneumomediastinum in pregnancy: Two case reports and a review of the literature, pathophysiology, and management. Obstet Gynecol 1984;64(suppl 3):39S-43S.

5. Simmons ST: A case of emphysema brought on by severe labor pains. Lond Med Common 1784;1:176.

6. Gordon CA: Respiratory emphysema in labor, with 2 new cases and review of 130 cases in literature. Am J Obstet Gynecol 1927;14:633-646. 7. Gray JM, Hanson GC: Mediastinal emphysema: Etiology, diagnosis, and treatment. Thorax 1966;21:325-332.

8. Macklin MT, Macklin CC: Malignant interstitial emphysema of the lungs and mediastinum as an important occult complication in many respiratory diseases and other conditions: An interpretation of the clinical literature in the light of laboratory experiment. Medicine 1944;23:281358.

9. Aisner M, Franco JE: Mediastinal emphysema. $N$ Engl $J$ Med 1949;241:818-825.

10. Crean PA, Stronge JM, FitzGerald MX: Spontaneous pneumomediastinum in pregnancy: Case report. Br J Obstet Gynecol 1981;88:952954.

11. Lam CA: Mediastinal and subcutaneous emphysema during labor: Report of a case. Obstet Gynecol 1967;29:378-381.

12. Hamman L: Mediastinal emphysema JAMA 1945;128:1-6.

13. Fagin ID, Schwab EH: Spontaneous mediastinal emphysema. Ann Intern Med 1946;24:1052-1072.

14. Hoffman AM, Pobirs FW, Merliss, R: Phonocardiogram in spontaneous interstitial emphysema of mediastinum. Am Heart $J$ 1943;26:686691.

15. Brandfass RT, Martinez DM: Mediastinal and subcutaneous emphysema in labor. South Med $J$ 1976;69:1554-1555.

16. Furst NJ, Lawrence LR: A case of bilateral pneumothorax, associated with pneumomediastinum, atelectasis, pulmonary edema and subcutaneous emphysema, occurring in labor: Mediastinal air block. Am $J$ Roentgenol 1949;62:798-806.

17. Horvick JH, West OT: Mediastinal and subcutaneous emphysema in early pregnancy. Obstet Gynecol 1954;4:606-610.

18. Spellacy WN, Konald A, Prem KA: Subcutaneous emphysema and pregnancy; Report of 3 cases. Obstet Gynecol 1963;22:521-523.

From the Department of Family Practice, USAF Medical Center, Scott, Il.

Reprint requests to Michael L. Sparacino, DO, Department of Family Practice, Scott Medical Center, Scott AFB, IL 62225. 


\section{American Osteopathic Association \\ Continuing Medical Education}

\section{CERTIFICATION OF HOME STUDY}

This is to certify that $I$,

activity for AOA CME credits.

Please print

completed the following

Type of activity (such as reading or listening)

Name of journal(s) or audio-tape and date(s) of issue(s):

(One-half CREDIT may be granted for each issue or tape)

MAIL TO: AOA Division of CME, 142 East Ontario Street, Chicago, Illinois 60611 KEEP A DUPLICATE FOR YOUR RECORDS!

The Home Study form is intended to document individual reading of recognized scientific journals, listening to approved audio-tapes, and other approved home study courses and programs under the criteria described for Category 2-B.

Only one type of home study, such as reading, should be indicated on a single form, though multiple issues of scientific journals may be listed.

This form should not be used, however, when CME quiz cards for the AOA Journal are submitted separately.

\begin{tabular}{|l|}
\hline FOR OFFICE USE ONLY \\
\hline Cat. $\frac{\text { 2-B Credits }}{\text { Date }}$ \\
Program \# \\
Doctor \# \\
Doctor's Name \\
\hline
\end{tabular}

Please refer to the revised CME GUIDE for additional information. 
EFFICACY...SAFETY...EXPERIENCE

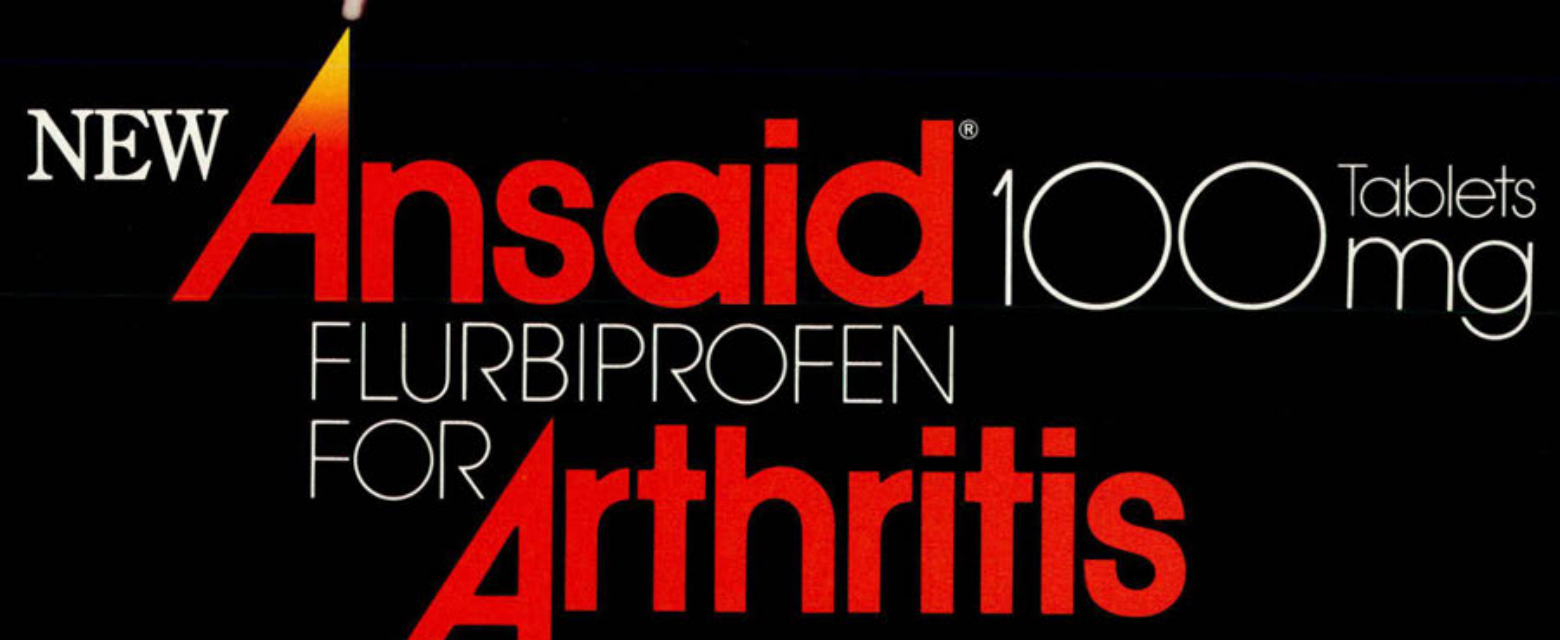




\section{AnsaidiOOmo: 1 Tablet BID or TID}

\section{for Osteoarthritis}

\section{Ansaid Tablets lessen}

disability in osteoarthritis

Reduction of disability (investigators' assessment) in a 12-week, double-blind, randomized study of 147 patients with osteoarthritis of the knee treated with Ansaid, up to $200 \mathrm{mg} /$ day or aspirin, up to $4,000 \mathrm{mg} /$ day.

\section{Percent patients improved}

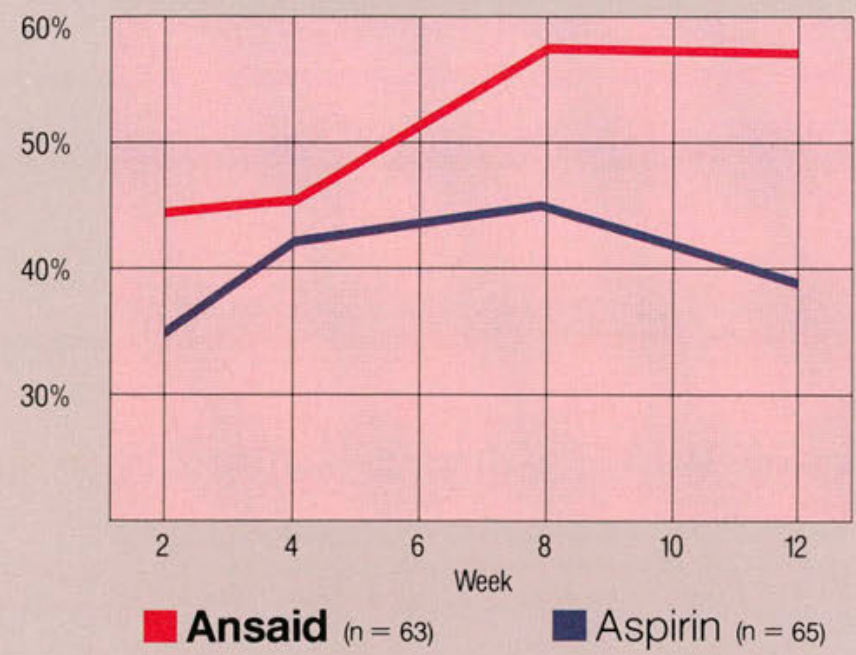

Ansaid (flurbiprofen) “... is an effective drug in controlling the pain and other symptoms of osteoarthritis of the knee.

\section{Convenient Dosage}

The dosage of Ansaid tablets is $200 \mathrm{mg}$ or $300 \mathrm{mg}$ daily, administered BID or TID. (Most experience in RA has been with TID or QID dosage.) Recommended starting dose is $100 \mathrm{mg}$ BID.

\section{Efficacy maintained} week after week 


\section{EFFICACY, \\ SAFETY, EXPERIENCE...}

\section{An excellent}

safety record worldwide

- A safety profile derived from 4,123 patients who received flurbiprofen.

948 of these patients were treated for at least 6 months.

- Overall incidence of side effects with Ansaid is about half that reported with comparable dosages of aspirin.

- Does not accumulate...excretion virtually complete 24 hours after the last dose.

Incidence of side effects in three body systems during clinical trials with Ansaid

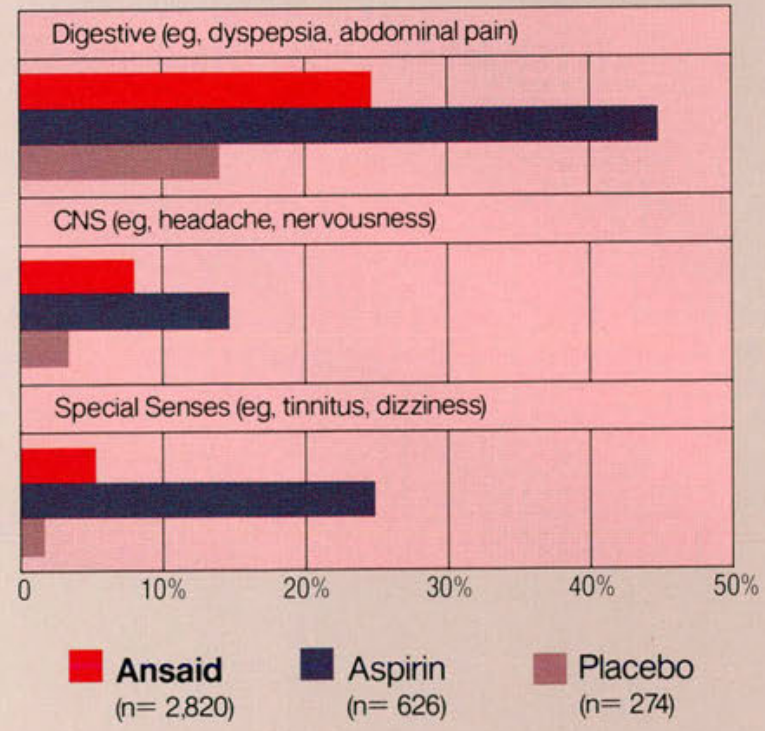

\section{Upjohn

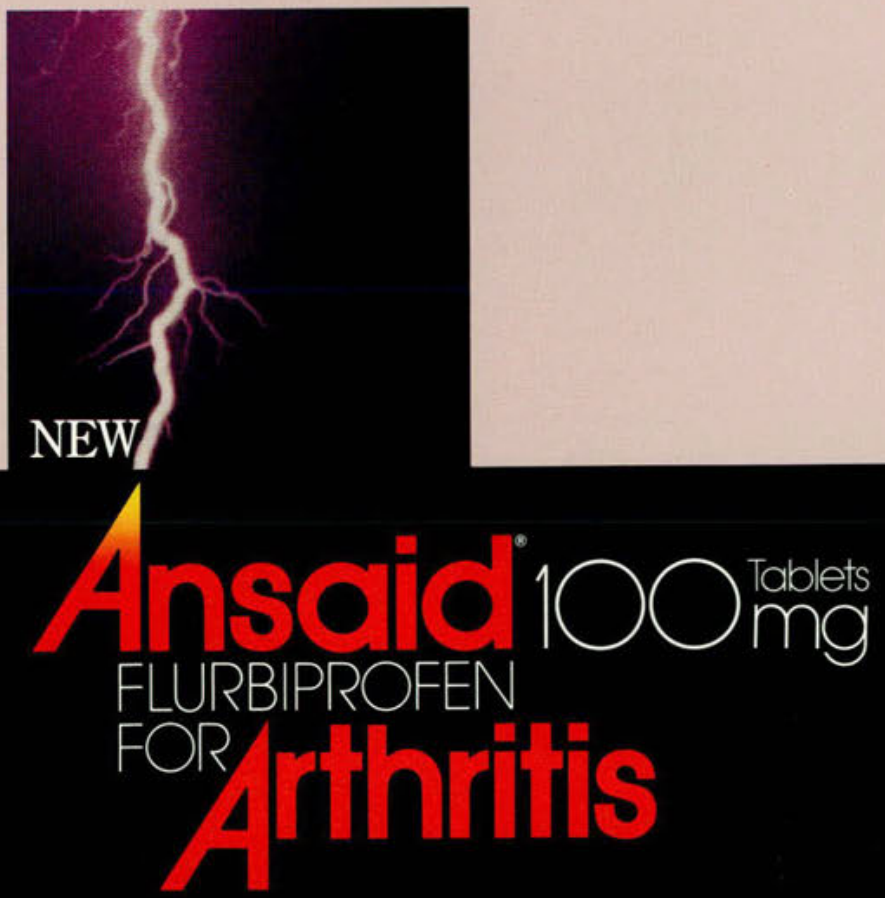




\section{Ansaid 100 mo: 1 Tablet BID or TID}

\section{for Rheumatoid Arthritis}

Ansaid Tablets: Effective in acute and chronic phases

Results of a 52-week, double-blind, randomized study of 822 patients in the United States, demonstrated that Ansaid 200 to $300 \mathrm{mg} /$ day relieves rheumatoid arthritis pain and inflammation as effectively as comparable dosages of aspirin.

\section{Convenient Dosage}

- The dosage of Ansaid tablets is $200 \mathrm{mg}$ or $300 \mathrm{mg}$ daily, administered BID or TID. (Most experience in RA has been with TID or QID dosage.)

Recommended starting dose is $100 \mathrm{mg}$ BID.

- Results of a 12-week study of 143 patients with rheumatoid arthritis comparing BID and QID dosing of Ansaid (flurbiprofen) $200 \mathrm{mg}$ daily indicated the BID dosing of Ansaid is as effective as QID dosing?
Improvement in efficacy parameters

Mean percent change from baseline

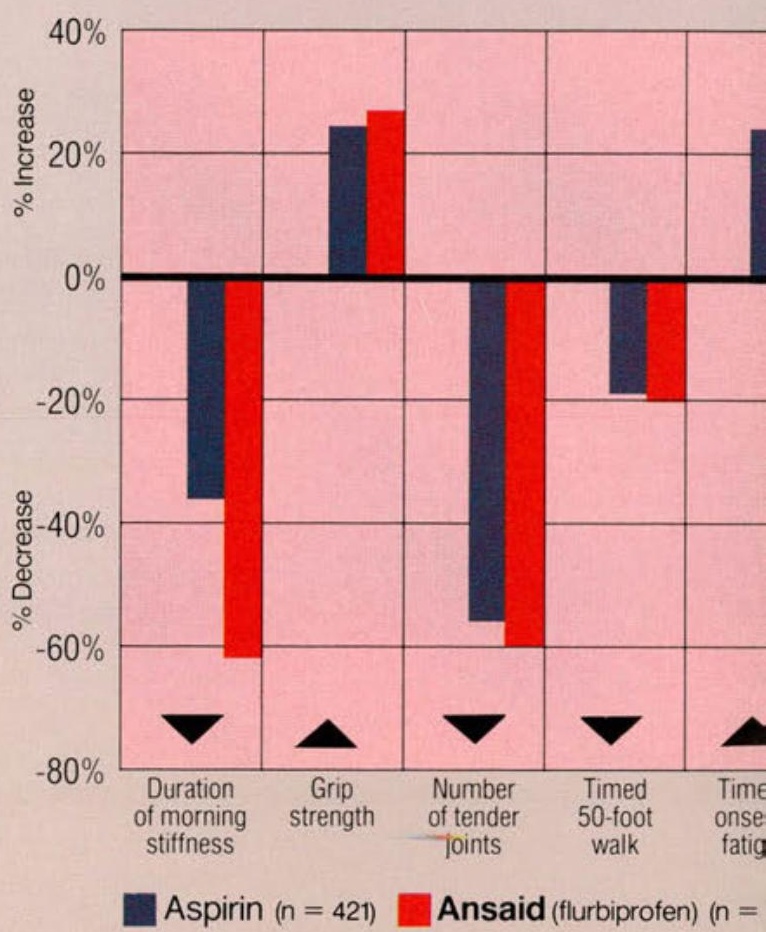

Effective...improves patient mobility. 


\section{EFFICACY, \\ SAFETY, \\ EXPERIENCE...}

\section{Over a decade of worldwide experience}

- Experience in 70 countries

- For over a decade, flurbiprofen has been a widely used antiarthritic agent.

- Since 1977, there have been more than 1 billion patient-days of treatment with flurbiprofen throughout the world.

- An 8-year study involving 1,396 patients in the United Kingdom confirms the efficacy and safety of flurbiprofen in arthritis. ${ }^{3-5}$

- A multicenter study of 11,500 arthritic patients in France provides additional confirmation of flurbiprofen efficacy and safety. ${ }^{6}$

- In the United States, controlled trials involving 2,820 patients further demonstrated the clinical efficacy and safety of Ansaid (flurbiprofen).
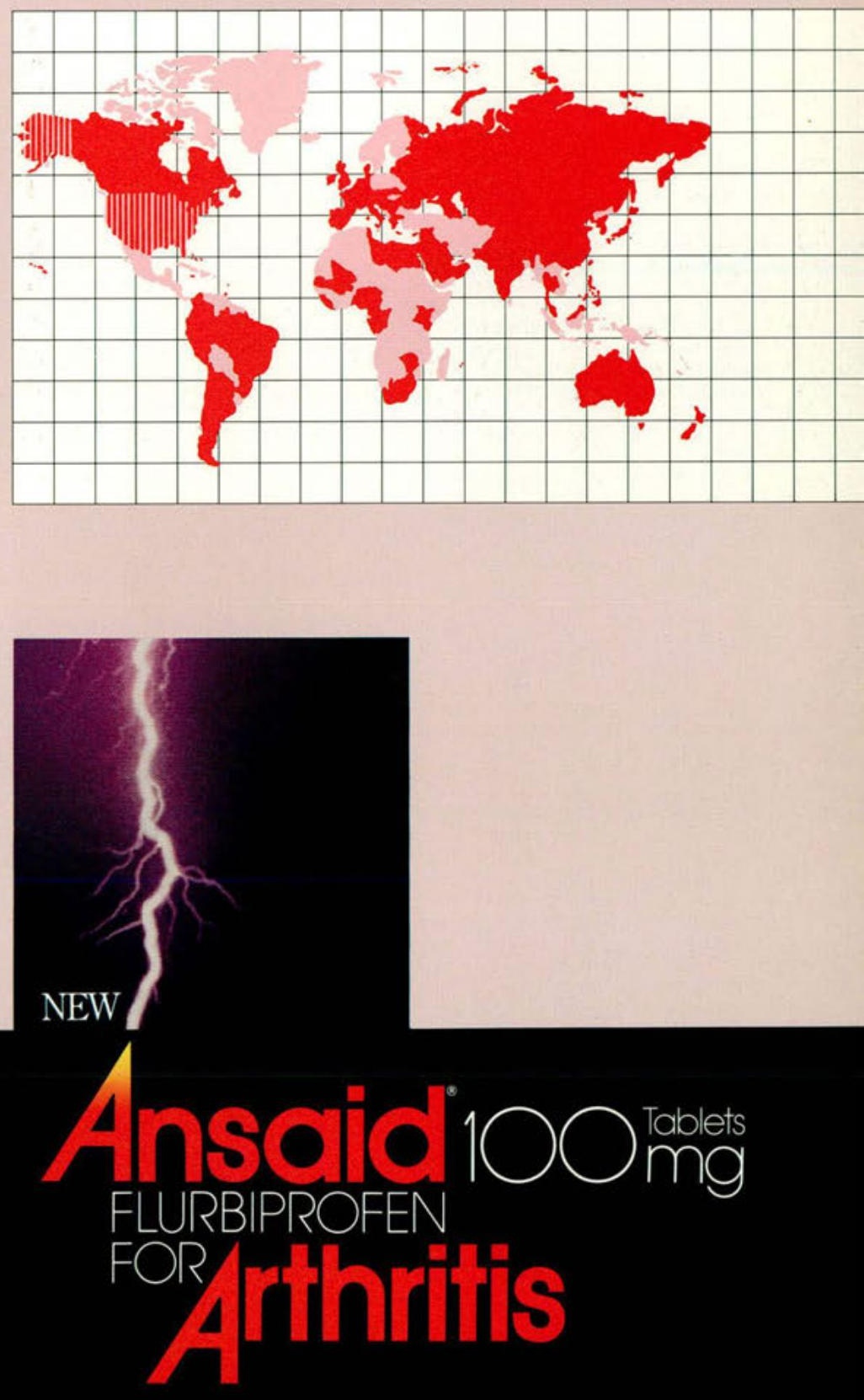


\section{EFFICACY, SAFETY, EXPERIENCE...}

The dosage of Ansaid tablets is

$200 \mathrm{mg}$ or $300 \mathrm{mg}$ daily, administered

BID or TID. (Most experience in

RA has been with TID or QID dosage.)

Recommended starting dose is $100 \mathrm{mg}$ BID.

ANSAID Tablets

(flurbiprofen)

INDICATIONS: Acute and long term treatment of signs and symptoms of rheumatoid arthritis and osteoarthritis. CONTRAINDICATIONS: Hypersensitivity to ANSAID, or if aspirin or any other nonsteroidal anti-inflammatory agent induces asthma, urticaria or other allergic type reactions. Fatal asthmatic reactions have been reported in such patients. WARNINGS: Gastrointestinal effects: Risk of Gl ulcerations, bleeding and perforation with nonsteroidal anti-inflammatory therapy: Serious Gl toxicity can occur at any time, with or without warning symptoms, during chronic treatment. The occurrence is about 1\% after 3-6 months, 2-4\% after a year. Patients should be informed of signs and symptoms of serious GI toxicity and what to do if it occurs. No subset of patients not at risk has been identified. Prior history of serious Gl events and other risk factors of peptic ulcer disease, e.g. alcoholism, smoking, etc., have been associated with increased risk. The elderly and debilitated tolerate ulceration and bleeding less well. Higher doses probably carry a greater risk. Gl ulceration and bleeding can occur without warning symptoms and chronically treated patients should be followed. PRECAUTIONS: Patients with impaired renal or hepatic function: Use ANSAID and similar agents cautiously. Pharmacokinetics have not been studied in patients with decreased liver function. Renal Effects: Rats develop rena papillary necrosis at dosages equivalent to human therapeutic levels, as do monkeys given 20-40 times the human dose. In clinical studies of ANSAID, kidney function tests were done monthly and renal effects were similar to those seen with other nonsteroidal anti-inflammatory drugs. A second form of renal toxicity has been seen in patients with prerenal conditions that reduce renal blood flow or blood volume. A nonsteroidal anti-inflammatory drug may cause dose-dependent reduction in prostaglandin formation and precipitate overt renal decompensation. Patients at greatest risk are those with impaired renal or hepatic function, heart failure, those taking diuretics or the elderly. Drug discontinuation usually leads to recovery. Patients at high risk on chronic treatment should have renal function monitored if they have signs or symptoms that may be consistent with mild azotemia, e.g., malaise, fatigue, loss of appetite. Occasionally BUN and serum creatinine may be elevated without signs or symptoms. Flurbiprofen is excreted by the kidneys and pharmacokinetics are changed by renal failure $s 0$ patients with renal failure should be monitored and may require a reduction of dosage to avoid accumulation of flurbiprofen metabolites. Liver tests: Borderline elevations of liver function tests may occur in up to $15 \%$ of patients, and may progress, remain unchanged or disappear with continued treatment. Patients with signs and/or symptoms or with an abnormal liver function test should be evaluated further Anemia: Patients treated long term who have initial hemoglobin values under $10 \mathrm{~g} / \mathrm{dL}$, should have periodic hemoglobin values. Fluid retention and edema: Fluid retention and edema have been reported so use ANSAID with caution in patients with conditions such as cardiac decompensation or hypertension. Vision Changes: Blurred and/or diminished vision has been reported. Patients with eye complaints should have periodic ophthalmologic exams. Effect on platelets and coagulation: Platelet aggregation is inhibited and bleeding time prolonged patients who may be adversely affected should be carefully observed. Information for patients: Physicians and patients may wish to discuss potential risks and likely benefits. Drug Interactions: Anticoagulants: Bleeding parameters are affected, clinical bleeding has been reported. Aspirin: Flurbiprofen levels were $50 \%$ lower. Concurrent use is not recommended. Betaadrenergic Blockers: Pharmacokinetics and heart rate reduction are not affected, hypotensive effect of propranolol but not atenolol was attenuated. Cimetidine, Ranitidine: Cimetidine causes a 13\% increase in area under the flurbiprofen serum concentration curve. Diuretics: Patients receiving furosemide or thiazides should be closely observed to make sure the desired effect is obtained.
Carcinogenesis, mutagenesis, impairment of fertility: No evidence. Teratogenic effe Pregnancy category B: No effect in animals. Not recommended for use in pregnancy. L and delivery, nursing mothers, pediatric use: Use is not recommended. ADVE REACTIONS: $9.4 \%$ of 4123 patients dropped out of studies because of an a di Incide $>1 \%$ : Gastrointestinal: Dyspepsia*, diarrhea*, abdominal pain*, nausea*, constipatior bleeding, flatulence, elevated liver enzymes and vomiting. Central nervous system: Headac "stimulation" (e.g. anxiety, insomnia, reflexes increased, tremor) and "inhibition" (e.g. amn asthenia, somnolence, malaise and depression). Respiratory: Rhinitis. Dermatologic: $R$ Special senses: Dizziness, tinnitus and changes in vision. Genitourinary: Signs and sympt suggesting a urinary tract infection* Body as a whole: Edema* Metabolic/nutritional: E weight changes. *Reaction in 3 to $7 \%$ of patients. Incidence $<1 \%$ (Causal relation. probable): Gastrointestinal: Peptic ulcer disease (See Warnings), gastritis, bloody diarr stomatitis, esophageal disease, hematemesis and hepatitis, cholestatic and non-choles jaundice. Central nervous system: Ataxia, cerebrovascular ischemia, confusion, paresthesia twitching. Hematologic: Decrease in hemoglobin and hematocrit, iron eosinophilia and ec mosis, thrombocytopenia, hemolytic anemia and aplastic anemia. (See Precautions) Respirat leukopenia, anemia, deficiency Asthma and epistaxis. Dermatologic: Angioedema, urtic eczema and pruritus; photosensitivity, toxic epidermal necrolysis and exfoliative derma Special senses: Conjunctivitis and parosmia. Genitourinary: Hematuria and impairment of function, interstitial nephritis. Body as a whole: Anaphylactic reactions, chills, fever. Metab Nutritional: Hyperuricemia. Cardiovascular: Heart failure, hypertension, vascular disease vasodilatation. Incidence < $1 \%$ (Causal relationship unknown): Gastrointestinal: Periodo abscess, appetite changes, cholecystitis and dry mouth. CNS: Convulsion, meningitis, hy tonia, cerebrovascular accident, emotional lability and subarachnoid hemorrhage. Hematolc Lymphadenopathy. Respiratory: Bronchitis, laryngitis, dyspnea, pulmonary embolism, puln ary infarct, hyperventilation. Dermatologic: Alopecia, nail disorder, herpes, dry skin sweating. Special senses: Ear disease, corneal opacity, glaucoma, retrobulbar neuritis, chan taste, transient hearing loss, retinal hemorrhage. Genitourinary: Menstrual disturbances, vas and uterine hemorrhage, vulvova itis, prostate disease. Metabc
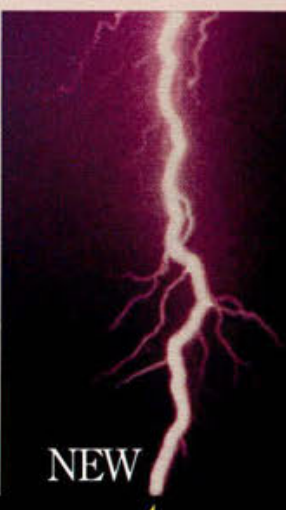

nutritional: Hyperkalem Cardiovascular: Arrhythmias, an pectoris and myocardial infarc AGE AND ADMINISTRATION: $300 \mathrm{mg}$ daily, administered bic or qid. (Most experience in rhel toid arthritis has been with tid o! dosage). Dose should be tailore severity of symptoms and pa: response. Store at controlled temperature $\left(15-30^{\circ} \mathrm{C}\right)$. Federal prohibits dispensing withor

\section{Upjohn}

The Upjohn Company Kalamazoo, MI 49001, US

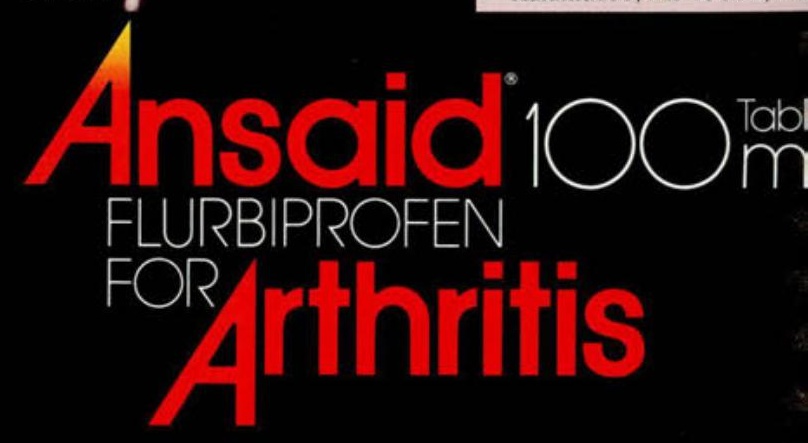

\section{References}

1. Lomen PL, Lamborn KR, Porter GH, et al: Treatment of osteoarthritis of the knee: A comparison of flurbiprofen and aspirin. Am JMed 1986; 80(suppl 3A): 97-102. 2. Brown BL, Daenzer CL. Hearron MS, et al: Comparison of two dosing schedules of flurbiprofen for patients with rheumatoid arthritis. Am J Med 1986; 80(suppl 3A): 19-22. 3. Busson M: A long-term study of flurbiprofen in rheumatological disorders: I. Rheumatoid arthritis. JInt Med Res 1986;14:1-6.

4. Busson M: A long-term study of flurbiprofen in rheumatological disorders: II. Osteoarthritis. JInt Med Res 1986;14:7-12. 5. Busson M: A long-term study of flurbiprofen in rheumatological disorders: III. Other articular conditions.

Int Med Res 1986;14:13-18.

6. Kieffer G: Flurbiprofen: A multicenter trial in 11,500 ambulatory patients (French). Rev Med 1981;22:915-924. 